perceptual curiosity in the rat, Journal of Comparative \& Physiological Psychology, $1955,48,238-246$.

DEMBER, W. N., EARL, R. W.. \& PARADISE N. Response by rats to differential stimulus complexity. Journal of Comparative \& Physiological Psychology, 1957, 50, 514-518.
DUTCH, J. Visual complexity and stimulus pacing in chicks. Quarterly Journal of Experimental Psychology, 1969, 21, 63-66.

THOMPSON, W. R., \& SOLOMON, L. M. Spontaneous pattern discrimination in the rat. Journal of Comparative \& Physiological Psychology, 1954, 47, 104-107.

\title{
Discrimination of orientation by rats
}

\section{MARCEL KINSBOURNE \\ Division of Pediatric Neurology, Duke Medical Center, Durham, N.C. 27706}

Learning to discriminate along the dimension of orientation, rats experienced decreasing difficulty depending on whether the figures were reversed, inverted, reversed and inverted, or rotated, relative to each other, a hierarchy identical to that previously established in humans.

Though rats can easily learn to discriminate horizontal lines from vertical, they cannot discriminate opposing obliques (Lashley, 1938) except in a situation specially designed to attract their attention to the orientational aspects of the total display (Kinsbourne, 1967). However, rats' ability to learn to discriminate the orientation of two-dimensional figures appears not to have been studied. Children have a notorious tendency to treat different orientations of a two-dimensional figure interchangeably, particulary when these are in mirror-image relation to each other (Rudel \& Teuber, 1963; Huttenlocher, 1967). Kinsbourne \& Hartley (1968) showed that children's relative difficulty in coping with orientation of a "p"-like ("lamb chop" of Wechsler \& Hagin, 1964) shape was consistently maximal for mirror-image reversed pairs, less for inversions, least for rotations. The hierarchy of confusions made by adults given brief exposures of arrays of the same materials similarly conformed to this sequence. They suggested a hierarchical search model to accommodate their findings. The question arises, is this hierarchy of relative confusibility a characteristic of human information processing or does it represent a more widely applicable strategy? In particular, does the postulated hierarchical search necessarily depend on verbal mediation? To resolve these questions, we confronted rats with the task of discriminating "lamb chop" shapes for reward.

\section{METHOD}

Twenty-eight male hooded rats were divided into four groups of seven each, matched for learning ability on a light-dark discrimination task. The experimental task was to discriminate, for food reward, pairs of "p" shapes. Each group was presented with a different pair of stimuli, as follows:

$$
\begin{array}{lll}
\text { Group } 1 & \stackrel{+}{\rho} q \\
\text { Group } 2 & \stackrel{+}{\rho} b \\
\text { Group } 3 & \stackrel{+}{\rho} d \\
\text { Group } 4 & \stackrel{+}{\rho} & 0
\end{array}
$$

Twenty trials were run on each of a series of consecutive days until attainment of a 9 out of 10 correct criterion or a total of 200 trials.
Table 1

\begin{tabular}{cccl} 
Group & $\mathrm{N}$ & $\begin{array}{c}\text { Number } \\
\text { Achieved } \\
\text { Criterion }\end{array}$ & \multicolumn{1}{c}{$\begin{array}{c}\text { Number of Trials } \\
\text { to Criterion }\end{array}$} \\
\hline 1 & 7 & 0 & \\
2 & 6 & 1 & 130 \\
3 & 6 & 2 & 110,130 \\
4 & 7 & 5 & $40,80,90,140,200$ \\
\hline
\end{tabular}

\section{RESULTS}

Two animals, one in Group 2 and one in Group 3, had to be withdrawn from the experiment because of sickness. The results with the remaining 26 animals are shown in Table 1. A Kruskal-Wallis one-way analysis of variance reveals significant variance between groups $(H=12, p<0.01)$.

\section{DISCUSSION}

The rats found it easiest to discriminate between the stimuli differing such that one was rotated relative to the other (Group 4). They experienced increasing difficulty with reversal and inversion (Group 3), inversion (Group 2), and reversal (Group 1), in that order. This hierarchy of difficulty corresponds exactly to that established under different circumstances for children and under yet other circumstances for adult humans by Kinsbourne \& Hartley (1968). The generality of this hierarchy excludes verbal mediation as the crucial factor. It is consistent with the view that differences in orientation are not interchangeable, but that there is a hierarchy of salience such that certain orientational disparities are more readily observed, remembered, or in the present instance, used as basis for a working hypothesis to determine the variable relevant to reinforcement. A hierarchical search (Johnson, 1967) is one way of conceptualizing such results.

\section{REFERENCES}

HUTTENLOCHER, J. Children's ability to order and orient objects. Child Development, 1967 , 38, 1169-1176.

JOHNSON, S. C. Hierarchical clustering schemes. Psychometrika, 1967, 32, 241-254.

KINSBOURNE, M. Sameness-difference judgments and the discrimination of obliques in the rat. Psychonomic Science, 1967, 7, 183-189.

KINSBOURNE, M., \& HARTLEY, D. Distinctive feature analysis in children's perception of simple shapes. Paper presented to Social Research \& Child Development, 1968.

LASHLEY, K. S. The mechanism of vision: XV. Preliminary studies of the rat's capacity for detail vision. Joumal of General Psychology, $1938,18,123-193$

RUDEL, R. G., \& TEUBER, H-L. Discrimination of direction of line in children. Joumal of Comparative \& Physiological Psychology, $1963,56,892.898$.

WECHSLER, D., \& HAGIN, R. A. The problem of axial rotation in reading disability. Perceptual \& Motor Skills, 1964, 19.319-326. 